\title{
Induced Vertical Disparity Effects on Local and Global Stereopsis
}

\section{Momeni-Moghaddam Hamed MSc. ${ }^{1}$; Eperjesi Frank PhD ${ }^{2}$; Kundart James O.D., MEd. ${ }^{3}$; Sabbaghi Hamideh BSc. ${ }^{4}$}

${ }^{1}$ Health Promotion Research Center, Zahedan University of Medical Sciences, Zahedan, Iran

${ }^{2}$ Ophthalmic Research Group, School of Life and Health Sciences, Aston University, Birmingham, B4 7ET, UK

${ }^{3}$ College of Optometry, Pacific University, Forest Grove, Oregon

${ }^{4}$ Zahedan University of Medical Sciences, Zahedan, Iran

Corresponding author: Hamed Momeni-Moghaddam MSc.

Postal address: Zahedan Optometry Department - School of Rehabilitation Sciences - Kafami Str. - Zahedan- Sistanobaluchestan - Iran

E-Mail: hmomeni opt $@$ yahoo.com

Tel Fax: +985413228445

Running title: Induced Vertical Disparity Effects on Stere 


\begin{abstract}
Purpose: Although significant amounts of vertical misalignment could have a noticeable effect on visual performance, but there is no conclusive evidence about the effect of very small amounts of vertical disparity on stereopsis and binocular vision. Hence, the aim of this study was to investigate of the effects of induced vertical disparity on local and global stereopsis at near.
\end{abstract}

Materials and Methods: Ninety participants wearing best-corrected refraction had local and global stereopsis tested with 0.5 and 1.0 prism diopter $(\Delta)$ vertical prism in front of their dominant and non-dominant eye in turn. This was compared to local and global stereopsis in the same subjects without vertical prism. Data were analyzed in SPSS.17 software using the independent samples $\mathrm{T}$ and the repeated measures ANOVA tests.

Results: Induced vertical disparity decreases local and global stereopsis. This reduction is greater when vertical disparity is induced in front of the non-dominant eye and affects global more than local stereopsis. Repeated measures ANOVA showed differences in the mean stereopsis between the different measured states for local and global values. Local stereopsis thresholds were reduced by 10 seconds of arc or less on average with $1.0 \underline{\Delta}$ of induced vertical prism in front of either eye. However, global stereopsis thresholds were reduced by over 100 seconds of arc by the same $1.0 \Delta$ of induced vertical prism.

Conclusion: Induced vertical disparity affects global stereopsis thresholds by an order of magnitude (or a factor of ten) more than local stereopsis. Hence, using a test that measures global stereopsis (such as the TNO) is more sensitive to vertical misalignment than a test such as the Stereofly that measures local stereopsis.

Key words: Binocular vision, Dominant eye, Global stereopsis, Local stereopsis, Vertical heterophoria 


\section{Introduction}

Stereopsis is the ability to discriminate relative distances between objects in space because of the horizontal separation of the two eyes, resulting in disparate retinal images. ${ }^{1}$ Disparity can be induced in horizontal, vertical, and oblique orientations, and can be further described as the difference between the retinal projections of the object of regard in space. ${ }^{2}$

Stereopsis is a very sensitive measure of binocular alignment and while fairly resilient to blur, stereopsis thresholds are known to decrease with heterophoria and heterotropia. It has also been reported that the binocular vision system can maintain normal function in the presence of vertical disparities misalignments from less than 10 minutes of arc (') to about four degrees of arc with no effect on stereopsis ${ }^{3}$, however, one study has found that, while stereopsis is minimally affected by horizontal heterophoria, it is sensitive to vertical misalignment. ${ }^{4}$

Vertical misalignments can result from several causes. Many are the result of cranial fourth nerve (trochlear) paresis. Vertical misalignment due to fourth nerve palsy is frequently primary and presumed congenital, but may also be caused by closed-head trauma. Often, these patients present with a head tilt towards the lower eye. Vertical disparity can also affect body posture and anterior-posterior sway. Better postural control has been reported for subjects without vertical phoria than subjects with vertical phoria. Authors mentioned greater postural instability in presence of even small amounts of vertical phoria (within the physiological range or $<1 \Delta$ ) in healthy subjects with vertical heterophoria. ${ }^{5}$ In another study Matheron et al. found that following induction of vertical disparity with a $2 \Delta$ base-down prism in the dominant and nondominant eye, a more accurate response was seen in the dominant eye compared to the non- 
dominant eye. They suggested postural control could be improved through the use of base down prism in front of the dominant eye. ${ }^{6}$

Differences between local stereopsis (such as that measured with the Stereofly stereotest) and global stereopsis (measured with the TNO stereotest) have been found in asthenopia. Symptomatic and asymptomatic subjects had a higher threshold with global stereotest (TNO) compared to local stereotest (Titmus). Using Receiver Operating Characteristic (ROC) curves, the cutoff point for symptomatology was 90 arc seconds for global stereopsis and 45 arc seconds for local stereopsis test. ${ }^{7}$ There are also reports of the presence of small vertical deviations when reasonable results are not achieved with vision therapy. ${ }^{8}$ These earlier investigations raise the question as to whether small amounts of vertical deviation (such as $0.5 \Delta$ or $1 \Delta$ ) can interfere in the process of binocularity. The aim of this study was to evaluate the effect of small vertical disparities on stereopsis to determine if the effects were different for local and global stereopsis.

\section{Materials and Methods}

In this study, students at Zahedan University of Medical Sciences were randomly selected. Ninety students, who met inclusion criteria and were given informed consent, were entered into the study. In addition, we assured subjects that their information was kept confidential in accordance with the tenets of the Declaration of Helsinki.

Inclusion criteria were listed in Table 1.

Table 1:

For determination of dominant eye, participants were asked to extend both of their arms in front of their body with palms facing outward so as to make a teardrop-shaped hole between their 
thumbs and index fingers. Then, they focused on a small optotype of the visual acuity chart in the center of hole on the other side of the examination room. With both of their eyes open, they were asked to close their right eye. If the object was still visible through the hole, then their left eye was dominant. If the object disappeared when they closed their right eye, then their right eye was dominant. ${ }^{9}$

Refractive error was determined by retinoscopy and was refined by subjective refraction and the dissociated red-green balance test. Near dissociated heterophoria was determined with the alternating prism cover test with best refractive correction in place, and the subject fixating on an accommodative target; a small letter E of approximately 6/9 size on a fixation bar was used. Measurement of the deviation was carried out with prism neutralization. The lowest power of prism that neutralized the recovery movement was taken as a measure of the deviation in prism diopters. For confirmation of the end point the subjective cover test was used. Subjects were asked to observe an apparent jump of the fixation target when the cover test was repeated.

For measurement of stereopsis, the Stereofly test which measures local stereopsis and TNO test which measures global stereopsis were used with the best correction in place. For the Stereofly test $^{\mathrm{a}}$, subjects wore polarizing spectacles and the booklet was held at $40 \mathrm{~cm}$. On this test, the disparities range from 3000 to 40 seconds of arc. The original Stereo Fly test consists of a largedisparity housefly, three rows of animals and nine sets of circles seen stereoscopically. The fly was shown first, and then subjects identified the one circle and animal that was disparate in each set. On each test, the lowest disparity that the subject was able to detect was recorded as his/her stereoacuity in seconds of arc. For the TNO test ${ }^{\mathrm{b}}$, subjects wore red and green anaglyphic filters 
and the booklet was held at distance of $40 \mathrm{~cm}$. Screening plates 1, 2, 3 and 4 were presented, and if the subject was able to successfully complete these pages, the graded plates from 480 to 15 seconds of arc were shown until the subject was unable to identify a three-dimensional shape correctly. The lowest discriminated disparity by each subject was recorded as the stereopsis in seconds of arc.

Vertical disparity was induced by small vertical prism of 0.5 and $1.00 \Delta$ base down over the dominant and non-dominant eye. In each condition, the subjects were asked about the awareness of physiological diplopia of a distance target that was on the wall for confirmation of the absence of suppression.

Stereopsis was first measured before vertical disparity was induced, and then measured with induced vertical disparity on the non-dominant and dominant eye. For odd-numbered subjects, testing was done with TNO test before Stereofly test and for even-numbered subjects, testing was done with Stereofly test first. All tests were done under standard near lighting.

After data collection, data were analyzed in SPSS.17 software using the independent-samples T, the repeated measures ANOVA, Bonferroni test for pairwise comparisons. In all tests, the significance level was considered to be 0.05 .

\section{Results}

Of our 90 participants (mean age \pm SD 20.97 \pm 1.25$), 64$ (71.1\%) were females and $26(28.9 \%)$ were males. The mean and SD spherical equivalents (SE) and cylinder power of right eye was $0.50 \pm 1.2 \mathrm{D}$ and $-0.16 \pm 0.3 \mathrm{D}$ and for left eye $-0.48 \pm 1.2 \mathrm{D}$ and $-0.18 \pm 0.4 \mathrm{D}$, respectively. The mean \pm SD of near horizontal deviation of all participants was $4.6 \pm 3.4 \Delta$ exophoria. The mean 
of the measured stereopsis with the TNO and the Stereofly tests and using induced small vertical disparity in the dominant and the non-dominant eye or in other words, before and after intervention are presented in Table 2.

Table 2:

A) About the TNO test:

Table 2 shows that induced vertical disparity decreases the stereopsis with the TNO (global) test, and also this reduction is higher when the vertical disparity induces in front of non-dominant eye.

A repeated measures ANOVA was used for comparison of mean stereopsis before and after the induced vertical disparity. This test showed differences in the mean stereopsis between the different measured states. The Bonferroni test was used for the pairwise comparisons. (Table 3)

Table 3:

The pairwise comparisons on the TNO test illustrate that mean stereopsis is not significantly different depending on whether the vertical prism is placed in front of dominant or non-dominant eye $(\mathrm{p}>0.05)$. There was a significant difference in the mean stereopsis between before and after inducing vertical disparity with $0.5 \Delta$ or $1 \Delta(\mathrm{p}<0.05)$.

Figures 1 shows the mean of the stereopsis with the TNO test. 
Figure 1:

B) About the Stereofly test:

According to the above table, it can be seen that induced vertical disparity decreases the stereopsis with the Stereofly (local) test with higher reduction when the vertical disparity is induceds in front of non-dominant eye.

Repeated measures ANOVA showed differences in the mean stereopsis between the different measured states. (Table 4)

Table 4:

The pairwise comparisons did not show statistically significant differences in mean stereopsis with the Stereofly test depending on whether vertical prism was placed in front of the dominant or non-dominant eye $(\mathrm{p}>0.05)$. Also, there was a difference of about 10 " of arc in mean stereopsis between before and after inducing vertical disparity with 1.0 prism diopter vertical prism in front of either their dominant and non-dominant eye in turn $(\mathrm{p}<0.05)$.

Figures 2 show the mean of the stereopsis with the Stereofly test.

Figure 2:

\section{Discussion}

The results of this study showed that even very small vertical misalignment of the eyes could have noticeable effect on the subject's visual performance, particularly in activities that require the individual to have a good stereopsis. Our findings demonstrate that stereopsis thresholds can be used to detect small vertical deviations. Even a $0.5 \Delta$ vertical disparity can significantly 
compromise depth perception, but only when a test that measures global stereopsis such as the TNO is used.

We also found that the reduction in stereopsis was higher but not statistically significant depending on whether vertical disparity was induced with prism in front of the dominant compared to the non-dominant eye. This is in agreement with the results of Matheron et al. who reported that the response to vertical disparity appears to be greater in the non-dominant eye. ${ }^{6}$ Kim et al. reported that there is an asymmetric vertical fusion response but they attributed it to causes other than the ocular dominance. ${ }^{10}$ Specifically, this study found that up to $1 \Delta$ vertical misalignment of the eyes caused less than 10" of change in local stereopsis thresholds (measured using the Stereofly test), regardless of which eye had the misaligning prism. Conversely, global stereopsis thresholds, as measured by TNO were decreased by $30-40$ " with $0.5 \Delta$ vertical prism, while $1 \Delta$ prism caused a decrease of $90-100 "$. Our results are in concordance with the results of Von Noorden et al. who reported that vertical heterophoria of $1 \Delta$ could cause symptoms and that hyperphoria of $0.5 \Delta$ was unlikely to do so. ${ }^{11}$ Our findings indicate however that even this amount of vertical disparity can have a substantial effect on binocularity. For this purpose, the measurement of stereopsis is a useful factor and a global test will be more useful than a local test. $^{7}$ Matheron et al. found small vertical prism and small vertical heterophoria is able to cause considerable changes in posture ${ }^{2,6}$ and Jackson et al. reported an association between small vertical heterophoria and motion sickness.- ${ }^{12}$

Another finding was that the standard deviations with prism were much higher than without prism. This is true as the SD for stereoacuity does increase for Stereofly and TNO with vertical prism compared to without vertical prism. This means that the stereoacuity values with the prism are more variable than without the prism. It must obviously be something to do with an effect of 
the prism on the binocular vision system since prism induces some stress on the binocular alignment.

Increasingly, visual performance measures are being used to evaluate how well a patient is seeing. Performance measures could include less common procedures like dynamic visual acuity, reading speed, and sport or video game ability. But the most accessible visual performance test is stereopsis. However, it is important for the researcher and clinician to be aware that not all stereopsis measures are equally sensitive, as we have demonstrated here. In particular a test that measures global stereopsis, such as the $\mathrm{TNO}$, is more sensitive to vertical misalignment than a test such as the Stereofly, which measures local stereopsis. 


\section{Conclusion}

Induced vertical disparity affects global stereopsis thresholds by an order of magnitude (or a factor of ten) more than local stereopsis. A vertical disparity of $0.5 \Delta$ can disrupt global but not local stereopsis while a vertical disparity of $1 \Delta$ affects both. This is important when it comes to test choice in the detection of subtle vertical eye misalignment.

Competing/conflicts of interest and funding sources: The authors indicate no conflicts of interest and funding support.

\section{Acknowledgments}

The authors would like to thank participants who made this study possible.

Table 1: Inclusion criteria.

\begin{tabular}{|c|c|}
\hline 1 & Best-corrected visual acuity $6 / 6$ or better in each eye at $6 \mathrm{~m}$ and $40 \mathrm{~cm}$ \\
\hline 2 & Absence of a strabismus at $6 \mathrm{~m}$ and $40 \mathrm{~cm}$ with cover test \\
\hline 3 & $\begin{array}{l}\text { Absence of vertical heterophoria with cover test and confirmed with the subjective cover test } \\
\text { (also known as the Phi test) }\end{array}$ \\
\hline 4 & No vertical fixation disparity with the near Mallett fixation disparity unit \\
\hline 5 & $\begin{array}{l}\text { Presence of at least a vertical vergence break point of } 4 \Delta \text { during vertical fusional vergence } \\
\text { measurement with a prism bar }\end{array}$ \\
\hline 6 & No history of eye and head trauma \\
\hline 7 & Normal eye and ocular health \\
\hline 8 & Presence of a motor dominant eye as determined using the Miles test \\
\hline
\end{tabular}


Table 2: Mean and SD of stereopsis with TNO and Stereofly tests before and after intervention.

\begin{tabular}{|c|c|c|}
\hline \multirow{2}{*}{ Stereotest } & Stereofly & TNO \\
\cline { 2 - 3 } & Mean \pm SD & Mean \pm SD \\
$(95 \%$ CI $)$
\end{tabular}

$\Delta:$ Prism diopter 
Table 3: Pairwise comparisons results ( $p$-value) for the TNO test depending on whether the vertical prism is placed in front of dominant or non-dominant eye.

\begin{tabular}{|c|c|c|c|c|c|}
\hline Different States & $\begin{array}{c}\text { No } \\
\text { Disparity }\end{array}$ & $\begin{array}{c}0.5 \Delta \text { in front } \\
\text { of dominant } \\
\text { eye }\end{array}$ & $\begin{array}{c}0.5 \Delta \text { in front } \\
\text { of non- } \\
\text { dominant eye }\end{array}$ & $\begin{array}{c}1 \Delta \text { in front } \\
\text { of dominant } \\
\text { eye }\end{array}$ & $\begin{array}{c}1 \Delta \text { in front of } \\
\text { non-dominant } \\
\text { eye }\end{array}$ \\
\hline No Disparity & ------- & 0.002 & $<0.001$ & $<0.001$ & $<0.001$ \\
\hline $\begin{array}{c}0.5 \Delta \text { in front of } \\
\text { dominant eye }\end{array}$ & ------- & 0.530 & 0.002 & $<0.001$ \\
\hline $\begin{array}{c}0.5 \Delta \text { in front of } \\
\text { non-dominant eye }\end{array}$ & & ------- & 0.046 & 0.009 \\
\hline $\begin{array}{c}1 \Delta \text { in front of } \\
\text { dominant eye }\end{array}$ & & & ------- & 1.000 \\
\hline
\end{tabular}


Table 4: Pairwise comparisons results (p-value) for the Stereofly test depending on whether the vertical prism is placed in front of dominant or non-dominant eye.

\begin{tabular}{|c|c|c|c|c|c|}
\hline Different States & $\begin{array}{c}\text { No } \\
\text { Disparity }\end{array}$ & $\begin{array}{c}0.5 \Delta \text { in front } \\
\text { of dominant } \\
\text { eye }\end{array}$ & $\begin{array}{c}0.5 \Delta \text { in front } \\
\text { of non- } \\
\text { dominant eye }\end{array}$ & $\begin{array}{c}1 \Delta \text { in front } \\
\text { of dominant } \\
\text { eye }\end{array}$ & $\begin{array}{c}1 \Delta \text { in front } \\
\text { of non- } \\
\text { dominant eye }\end{array}$ \\
\hline No Disparity & -------- & 0.24 & 0.25 & 0.04 & 0.04 \\
\hline $\begin{array}{c}0.5 \Delta \text { in front of } \\
\text { dominant eye }\end{array}$ & -------- & 1.00 & 0.24 & 0.23 \\
\hline $\begin{array}{c}0.5 \Delta \text { in front of } \\
\text { non-dominant eye }\end{array}$ & & -------- & 0.13 & 0.16 \\
\hline $\begin{array}{c}1 \Delta \text { in front of } \\
\text { dominant eye }\end{array}$ & & & ------- & 1.00 \\
\hline
\end{tabular}




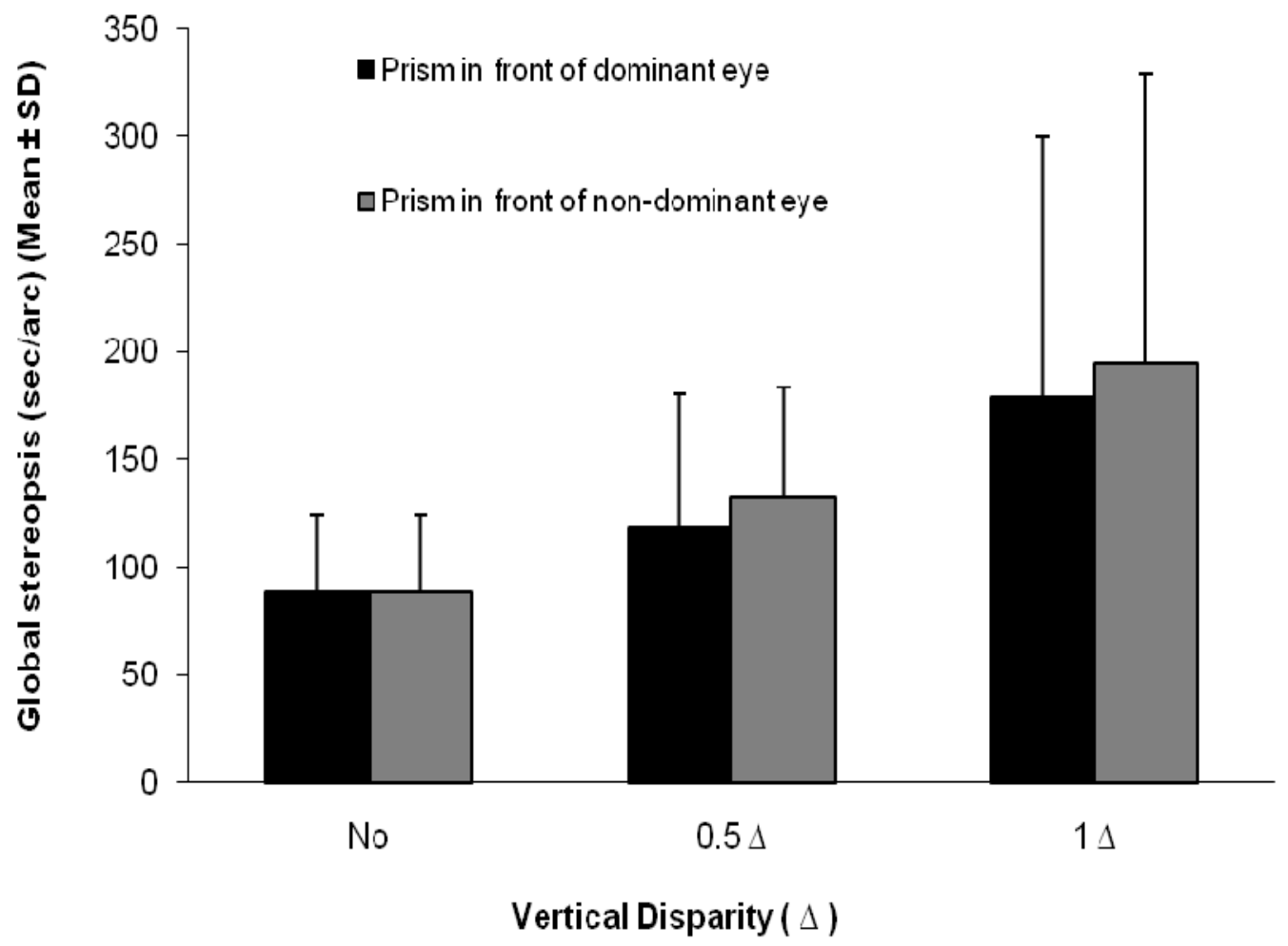

Figure 1: Mean global stereopsis as measured with the TNO test. Variation with dominancy and amount of vertical disparity. 


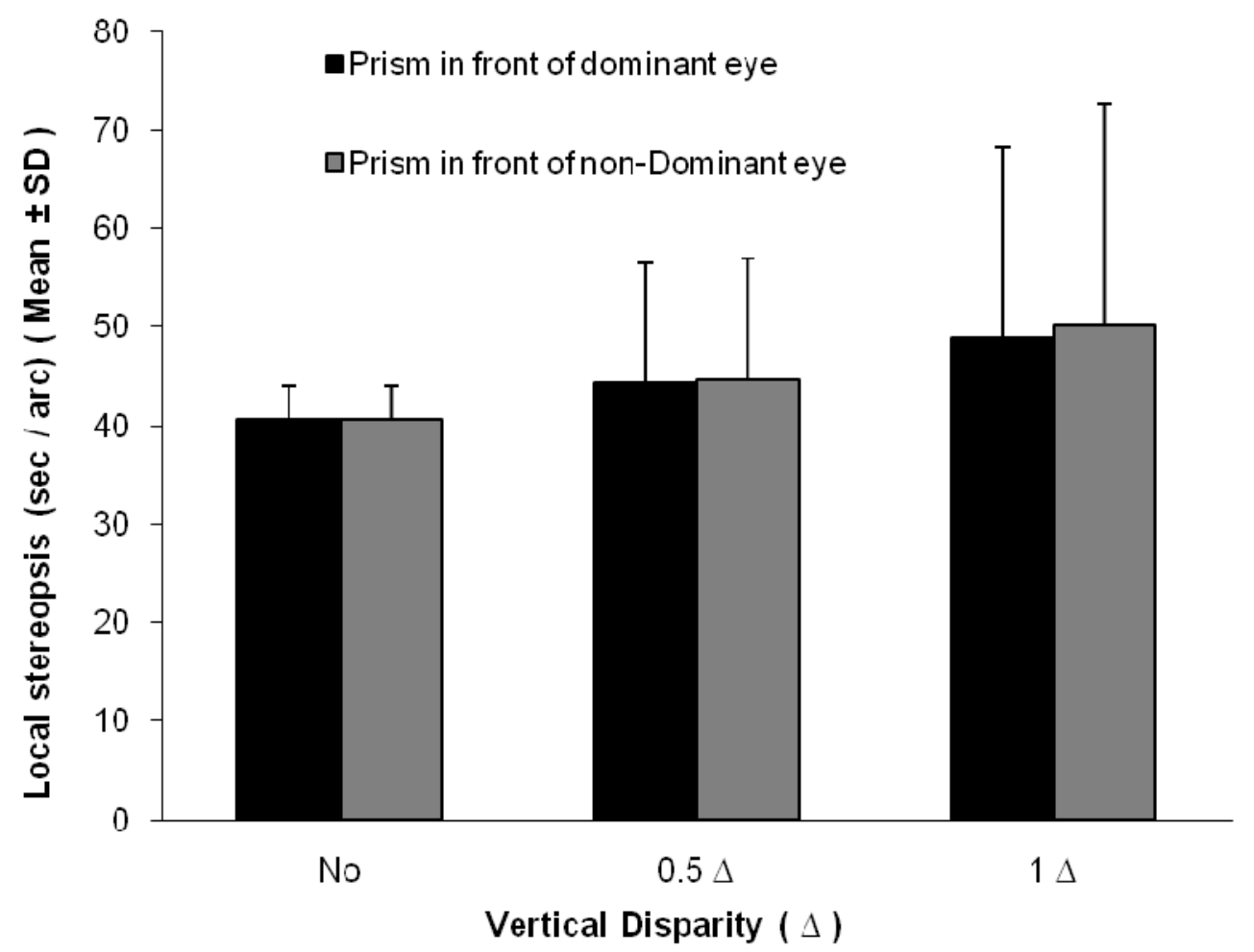

Figure 2: Mean local stereopsis as measured with the Stereofly test. Variation with dominancy and amount of vertical disparity. 


\section{References}

1. Brown AM, Lindsey DT, Satgunam PN, Miracle JA: Critical Immaturities Limiting Infant Binocular Stereopsis. Invest Ophthalmol Vis Sci 2007;-48-(3):1424-34.

2. Matthews N, Meng X, Qian N: A physiological theory of depth perception from vertical disparity. Vision Research 2003;-43:-85-99.

3. Fukuda K, Wilcox LM, Allison RS, Howard IP: A reevaluation of the tolerance to vertical misalignment in stereopsis. Journal of Vision 2009;-9(2):1,-1-8.

4. Jiménez JR, Rubiño M, Díaz JA, Hita E, del Barco LJ: Changes in stereoscopic depth perception caused by decentration of spectacle lenses. Optom Vis Sci 2000;-77(8):-421-7.

5. Matheron E, Kapoula Z: Vertical phoria and postural control in upright stance in healthy young subjects. Clin Neurophysiol 2008;-119(10):-2314-20.

6. Matheron E, Lê TT, Yang Q, Kapoula Z: Effects of a two-diopter vertical prism on posture. Neurosci Lett 2007;-423-(3):236-40.

7. Momeni-Moghadam H, Kundart J, Ehsani M, Gholami K: Stereopsis with TNO and Titmus Stereo Tests in Symptomatic and Asymptomatic University Students. Journal of Behavioral Optometry 2012;-23(2):38-42.

8. Scheiman M, Wick B: Clinical Management of Binocular Vision: Heterophoric, Accommodative and Eye Movement Disorders, 3th ed. Philadelphia: Lippincott Willians \& Wilkins, 2008.

9. Mendola JD, Conner IP: Eye dominance predicts fMRI signals in human retinotopic cortex. Neurosci Lett. 2007;-414(1):30-4. 
10. Kim JK, Hayden AM, Sadun EA, Sebag J, Sadun AA: Response pattern asymmetry of binocular vision vertical fusion amplitudes in a normal population. Binocul Vis Strabismus Q $2008 ;-23(1): 23-30$.

11. Von Noorden G, Compas K: Binocular vision and ocular motility Theory and management of strabismus. 6th ed. CV, Mosby, 2002.

12. Jackson DN, Bedell HE: Vertical heterophoria and susceptibility to visually induced motion sickness. Strabismus 2012;-20(1):17-23.

${ }^{a}$ Stereo Optical Co., Inc. 8623 W. Bryn Mawr Ave., Suite 502, Chicago, IL 60631.

${ }^{\mathrm{b}}$ Sussex Vision International, A2 Dominion Way, Rustington, West Sussex, BN16 3HQ, United Kingdom. 